\title{
A Mobile Healthcare Application for Chronic Disease Patient
}

\author{
Amr Salah Mahmoud \\ Master Student, Information Systems, College of Computer and Information Sciences, King Saud University \\ amrwitiion@yahoo.com
}

\begin{abstract}
This paper presents a personalized food advisory application that can be used by chronic disease patients to manage and control their food intake. The application was developed as an Arabic Android application for mobile devices. The preliminary result confirms the importance of having such application to assist chronic diseases patients to follow the nutrition facts. Almost all the participants are willing to recommend the proposed system to their patients.
\end{abstract}

Keywords: Healthcare; Chronic Disease; Android; nutrition facts; mobile Application.

\section{INTRODUCTION}

The rate of Chronic Diseases has increased across the world, dramatically enlarging the percentage of people suffering from Heart diseases problems and chronic diseases.

Patient education has long been considered an important part of treatment for conditions where lifestyle modifications improve disease control. In particular, dietary modifications have been shown to be beneficial for chronic diseases, such as type 2 diabetes, hypertension,

and hyperlipidemia $[1,2]$.

mobile health (m-health) research has focused more on specific applications and proof of concept studies [3] rather than the examination of generic principles or the analysis of critical success factors. Such work seldom addresses the socioemotional impacts of chronic conditions or emerging issues such as the change from a biomedical model of healthcare to the concept of the patient as customer and patient empowerment through self-management. The need to approach m-health research from a more holistic standpoint is supported by a report on m-health in New Zealand which acknowledges that 'technology is the easy part [4].

Hypertension and arrhythmia are chronic diseases, which can be effectively prevented and controlled only if the physiological parameters of the patient are constantly monitored, alongwith the full support of the health education and professional medical care [5]

In an age where chronic diseases are becoming endemic, the need to mitigate the social, medical and economic effects on both individuals and the national economy is becoming acute. The prevalence of these diseases has emphasized the importance of information and communication technologies (ICT) that share essential information across the chain of care associated with chronic disease management [6,7].

In recent years, healthcare for elderly people has been an important research topic. The commonly seen chronic diseases for elderly people include hypertension and arrhythmia. The current healthcare for such diseases is still mainly from outpatient services. Due to the development of information and communication technology (ICT), the feasibility of home telecare has been highly raised. In the literature, the telecare services were first provided by utilizing traditional public switched telephone network (PSTN). Lee et al. used a cable television (CATV) network to transmit electrocardiogram (ECG) data to healthcare center and to provide function of video conversation between healthcare providers and patients [8].

On the other hand, mobile devices market is becoming the largest market with devices of reduced sizes and costs and increased functionalities. Using mobile phones for health Applications are becoming visible in the market as they provide many opportunities to improve the quality of life through ubiquitous health applications [9].

The paper describes the complete process beginning from the software requirements gathering in section 2, system design and architecture in section 3, implementation in section 4 and ending with testing and evaluating the fully running application in section 5 . The summary and conclusions of the papers are presented in section 6 . 


\section{ANALYSIS}

In a Chronic Disease Patient Application (CDPA), we followed the Spiral model as it is maintainable and easy to use. Additionally, CDPA has a Medium to High-size scope with very low risks and requirements are clear from the start; these are contain 13 Chronic Disease A. Requirements Analysis

In collecting the software requirements, we have followed functional steps:

- Registration step: we developed a brief online Arabic Form, shown in Figure 2, the user inserts his information which saved in cloud and we use

- Age

- Gender

- Weight

- User choose the disease

To calculate the calories and other value in figure 1

C-WHO Equations Depend on (WHO, 2007).

\begin{tabular}{|l|c|c|}
\hline AGE & FEMALE & MALE \\
\hline 3-9 years & $22.5 \mathrm{w}+499$ & $22.7 \mathrm{w}+495$ \\
\hline $10-17$ years & $12.2 \mathrm{w}+746$ & $17.5 \mathrm{w}+651$ \\
\hline $18-29$ years & $14.7 \mathrm{w}+496$ & $15.3 \mathrm{w}+679$ \\
\hline $30-60$ years & $8.7 \mathrm{w}+829$ & $11.6 \mathrm{w}+879$ \\
\hline$>60$ years old & $10.5 \mathrm{w}+596$ & $13.5 \mathrm{w}+487$ \\
\hline
\end{tabular}

Fig. 1. Calories calculation table

This application has a feature of monitoring most chronic diseases, which is not available in any applications.in figure 2 .

\begin{tabular}{|c|c|c|c|c|c|c|c|c|c|}
\hline \multirow[b]{2}{*}{ Disease } & \multirow[b]{2}{*}{ night } & \multicolumn{8}{|c|}{ Nuritional Care } \\
\hline & & Energy (Cabiones) & Protein & Fat & Sodaiom & Caroohydrates & $\begin{array}{c}\text { Dietary } \\
\text { fibor }\end{array}$ & cholesterto. & Potassium \\
\hline Angina Pectonis & $x$ & Y & $x \times 15$ & $10 \%$ of calories & $3000 \mathrm{mg}$ & $60 \%$ of total calc & $25 \mathrm{~g}$ & $300 \mathrm{mg}$ & $2500 \mathrm{~g}$ \\
\hline Atteriosclerosis Patients & $x$ & Y & $x \times 15$ & $10 \%$ of calories & $3000 \mathrm{mg}$ & $60 \%$ of total calc & $25 \mathrm{~g}$ & $300 \mathrm{mg}$ & $2500 \mathrm{~g}$ \\
\hline Cardiac Cachexia & $x$ & Y & $\times 15$ & $10 \%$ of calories & $3000 \mathrm{mg}$ & $60 \%$ of total cath & & $300 \mathrm{mg}$ & $2500 \mathrm{~g}$ \\
\hline Congestive Heart Failure & $x$ & $Y$ & $\times 15$ & $25 \%$ of calories & $3000 \mathrm{mg}$ & $55 \%$ of total calc & & $300 \mathrm{mg}$ & $2500 \mathrm{~g}$ \\
\hline Coronary Heart Attack & $x$ & Y & $x \times 15$ & $10 \%$ of calories & $3000 \mathrm{mg}$ & $60 \%$ of total calt & & $300 \mathrm{mg}$ & \\
\hline Heart Surgery & $x$ & $Y$ & $x: 8$ & $25 \%$ of calories & $2000 \mathrm{mg}$ & $50 \%$ of total calc & & & \\
\hline Heart Transplant & $x$ & Y & $\times 15$ & $20 \%$ of calories & $2000 \mathrm{mg}$ & $55 \%$ of total calc & & & $2500 \mathrm{~g}$ \\
\hline Heart Valve & $x$ & Y & $x \times 15$ & $10 \%$ of calories & $3000 \mathrm{mg}$ & $60 \%$ of total calt & & $300 \mathrm{mg}$ & $2500 \mathrm{~g}$ \\
\hline Hyperinidemia & $x$ & Y & $x+15$ & $\leq 30 \%$ of total calories. & $2000 \mathrm{mg}$ & $55 \%$ of total calt & & $300 \mathrm{mg}$ & $2500 \mathrm{~g}$ \\
\hline Hypertension & $x$ & Y & $x$ & $25 \%$ of calories & $240 \mathrm{mg}$ & $50 \%$ of total calt & & & $2000 \mathrm{~g}$ \\
\hline Hypertrigyceridemia & $x$ & Y & $x \times 15$ & $10 \%$ of calories & $3000 \mathrm{mg}$ & $60 \%$ of total cal & & $300 \mathrm{mg}$ & $2500 \mathrm{~g}$ \\
\hline Myocardial Infarction & $x$ & Y & $\times 115$ & $10 \%$ of calories & $3000 \mathrm{mg}$ & $60 \%$ of total cath & & $300 \mathrm{mg}$ & $2500 \mathrm{~g}$ \\
\hline Rheumatic ferer & $x$ & Y & $\times 15$ & $15 \%$ of calories & $3000 \mathrm{mg}$ & $55 \%$ of total cath & & & $2500 \mathrm{~g}$ \\
\hline
\end{tabular}

Fig. 2. Relation between chronic diseases and his nutritional care

\section{A. Product Features}

The most important features of CDPA include:

- A user-friendly Arabic Application

- Supports Android devices.
- Investigate the effect of food on chronic diseases.

- The user can choose one disease or more and the function calculate the maximum allowed Nutritional value of food available

- The user can read the barcode of any product using mobile camera

- The user can search and show product nutrition details shown in Figure 3

- Alerts the user for products.

- Provides password-secured access to data and information.

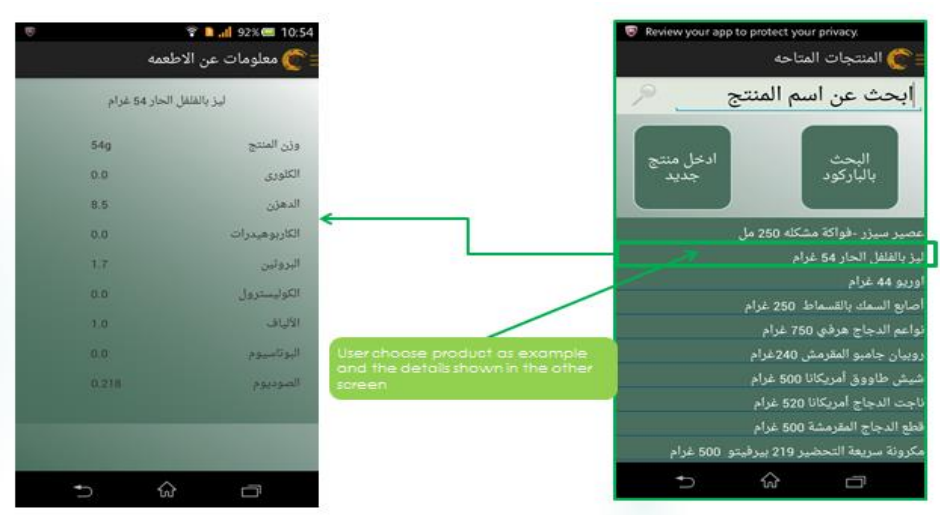

Fig. 3. Search method on application

\section{DESIGN}

Basically, the system is composed of three software components: The mobile application with embedded database, the server and the execution environment. System Architecture in figure 5. The user/patient scans the food product barcode or searching by product name from anywhere

The User/patient is presented in the heart of a Personalized Health Care composed of main actors/agents. Here the user/patient who suffers from chronic diseases or Sensitivity of any food kind or beverage uses this system to help him to avoid any of these products which is detrimental to his health. To solve this issue, we proposed our Health Care application which is based on the idea of sharing the scientific names of the materials which the food and beverage contain of it and compares it with the Materials that are not permitted for the patient, between different users, via mobile devices and networks. In this way, there will be no constraints such as the mandatory presence to review the doctor office. Checking the food and beverage which is not allowed for the patient, it will be achieved via mobile devices connected via networks anywhere and anytime. 


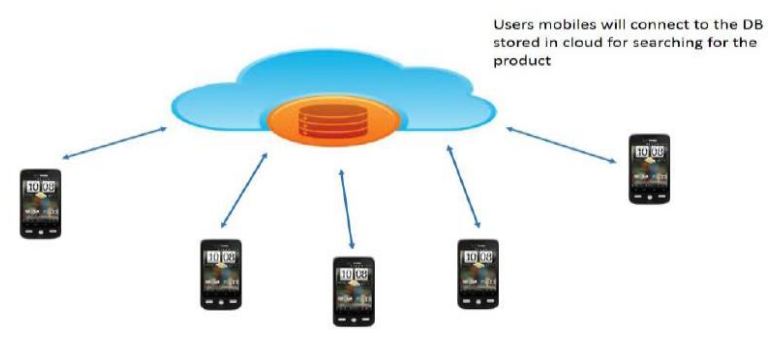

Fig. 4. System Architecture (CDPA)

\section{IMPLEMENTATION}

\section{A. Implementation and Execution Environments}

Hardware Specification:

- Smart phones: an Android smart phone is required to run the application after development.

- Computers: personal computers or laptops are required during development.

Software Specification:

Several software tools were required to develop the application with its embedded database:

- Emulator (SDK).

- Eclipse-Java to compile the code.

- Android platform 2.2 (Google API 8).

- Arabic libraries.

For Smartphones we needed:

- Network communication: full Internet access for search products and check the barcode

\section{B. Database Implementation}

I try to enhance the speed of the Application (CDPA) by two ways:

- Try to make most of data using in equations as parameter in the application (CDPA) locally in the app to decrease need to connect to the Internet.

- Choose the fast way in search in database so I choose Parse.com which using combination of NoSQL and Relational SQL.

Then I consider using free hosting to decrease the cost of the app so I can make the app free for users therefore, I search and find one of the best solutions is using Parse.com

For many reasons:

- It is for free

- It using combination of many type of Database as Mongo DB (NOSQL) and Relational SQL
- Due to using NOSQL, it is very fast in searching and compares data in server.

\section{User Interface and Mobile Application}

We consider the most challenging part of our project to be creating a mobile interface that is user-friendly, while offering all functions expected by end users.

The first page is the Login Page, shown in Figure 5. This page contains two fields: one for the username and the other for the password.

The second page is the registration Page "Profile page", shown in Figure 6. This page contains the key functions of the application are contains the goal weight, age, weight, gender and At the bottom there is a chronic disease button which transfers users to the Chronic Disease Page to determine the chronic disease type, shown in Figure 7

The third page is the products page, shown in figure 8 that contain the availability of products, can search for any product by using barcode, shown in figure 9 and add new product

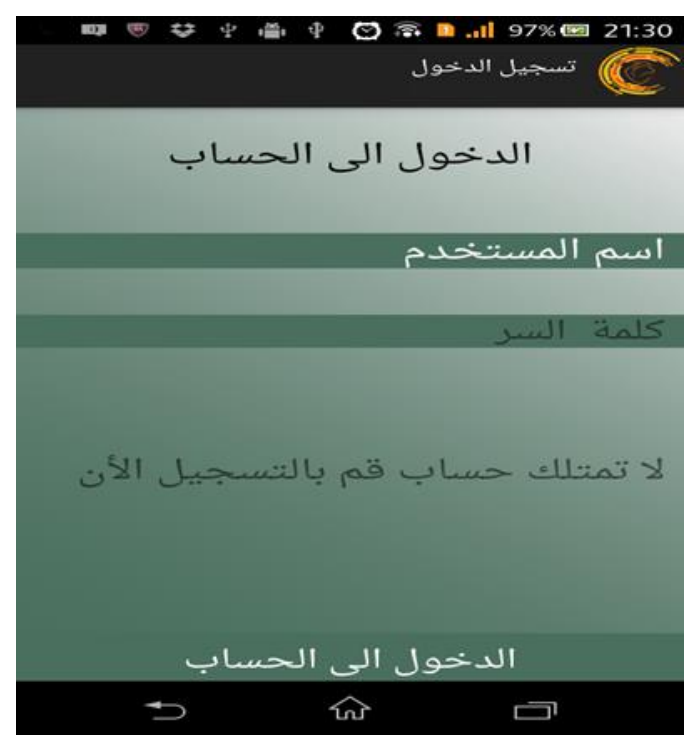

Fig. 5. Login Page 


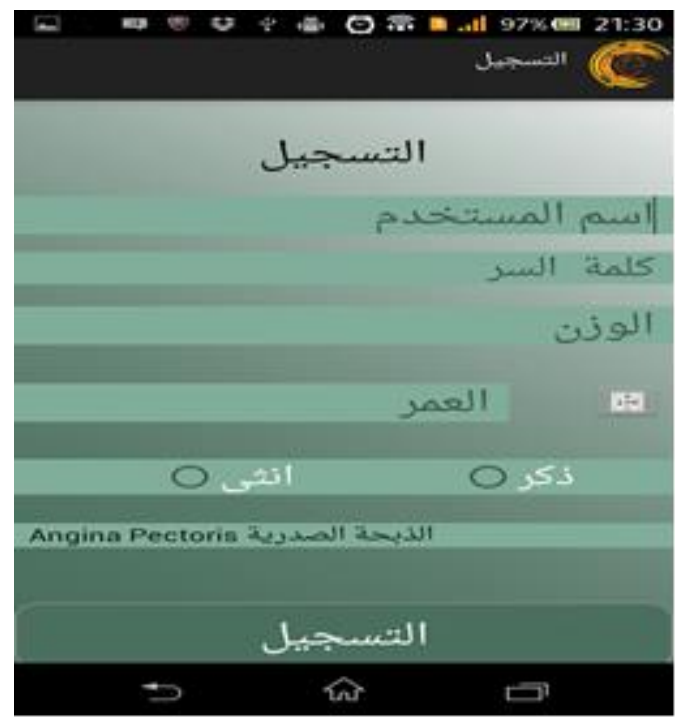

Fig. 6. Registration Page

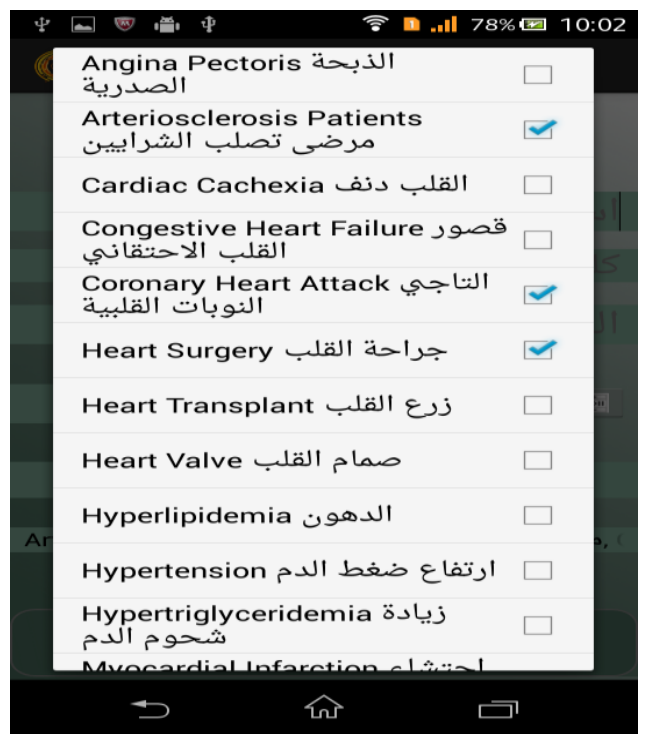

Fig. 7. The Chronic Disease Page

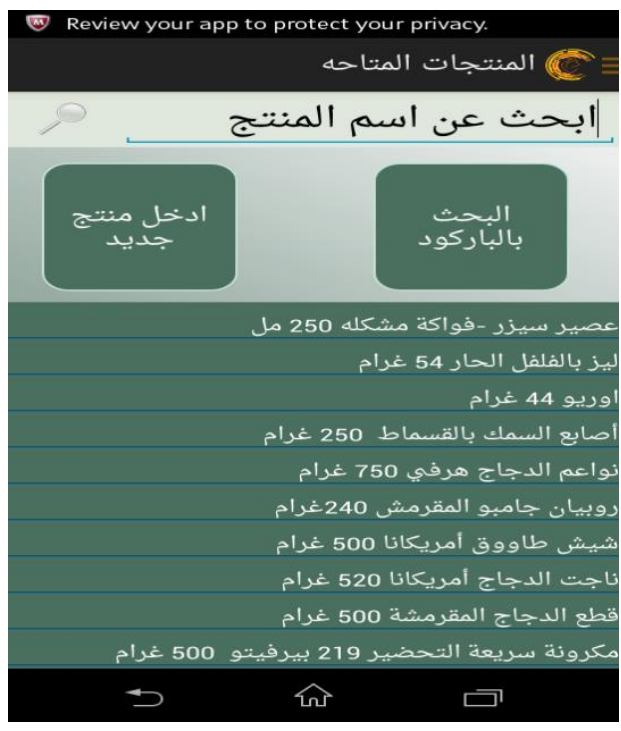

Fig. 8. Products

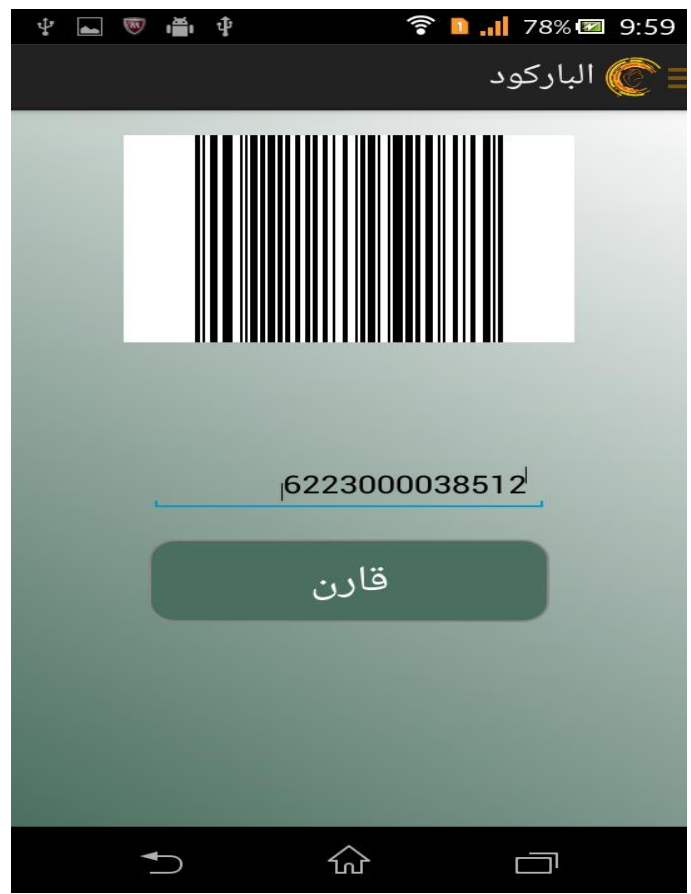

Fig. 9. .Searching Barcode page 


\section{TESTING AND EVALUATION}

We set a general work plan to test CDPA in a continuous manner, so we started by testing each unit separately, then we tested for correct integration between units and finally we tested the functionality of the whole system.

In integration testing, we insured that all application pages with links have correctly-working links. For each application page connecting to the database, we insured that the connection is functioning and that the returned results are correct. This integration testing was also among the most difficult jobs we have gone through in this project. As sometimes a database table was working correctly and a page is also functioning perfectly.

After successfully solving all the integration problems, we were able to test the entire system. We examined the overall functionality of the application, ensuring that high priority requirements of the application are implemented. Testing the CDPA system was by first converting the code to .APK file, and downloading it on three Samsung Galaxy STM II Android Smartphone to find disparities between implementation and specifications.

Even though the evaluation of such application is difficult, it is planned to be carried out as a next phase for this project. A scientific group including programmers, patients would carry out a detailed evaluation of the content in a form of a cognitive walkthrough.

\section{CONCLUSION}

Year after year, the rate of mobile health care application has increased across the world, alarming of many heart and chronological diseases. Use of mobile phones for health applications has been visible in the market and has provided many opportunites to improve the quality of life at reduced costs and efforts. This paper presents the complete process of developing an Arabic Android application called CDPA, which utilizes and integrates many tools and technologies to help in tackling the chronic diseases. The process included many phases beginning from the software requirements gathering

and ending with the testing and evaluating of a fully running application.

There are several near future tasks that would complement this work. We need to add more diet plans and food nutrition information. Also, we need to add more functions to promote exercising. We intend to create a supporting website for the application with additional features and functionalities. Additionally, we are preparing to conduct a systematic evaluation of the application in a form of a cognitive walkthrough and a pilot study with a specialized research team. It is our hope, through conducting this work, to have CDPA contributing to the preservation of

public health.

\section{REFERENCES}

[1] American Diabetes Association, Bantle JP, Wylie-Rosett J, Albright AL, Apovian CM, Clark NG, Franz MJ, Hoogwerf BJ, Lichtenstein AH, Mayer-Davis E, Mooradian AD, Wheeler ML. Nutrition recommendations and interventions for diabetes: A position statement of the American Diabetes Association. Diabetes Care. 2008;31(suppl 1): S61-S78.

[2] Appel LJ, Moore TJ, Obarzanek E, Vollmer WM, Svetkey LP, Sacks FM, Bray GA, Vogt TM, Cutler JA, Windhauser MM, Lin PH, Karanja N. Aclinical trial of the effects of dietary patterns on blood pressure. DASH Collaborative Research Group. $N$ Engl J Med. 1997;336:1117-1124.

[3] Guruajan R, Murugesan S. Wireless solutions developed for the Australian Healthcare: A Review.Paper presented at the 4th International Conference on Mobile Business, Sydney, Australia, 2005.

[4] Miller M. Mobile Health Survey. Auckland: Vodafone Health Division, 2005.

[5] Ren-Guey Lee, Member, IEEE, Kuei-Chien Chen, ChunChieh Hsiao, and Chwan-Lu Tseng "A Mobile Care System With Alert Mechanism" IEEE Trans. Inf. Technol. Biomed., VOL. 11, NO. 5, 2007

[6] Alpay L, Toussaint P, Zwetsloot-Schonk B. Supporting healthcare communication enabled by information and communication technology: can HCI and related cognitive aspects help? Paper presented at the Dutch Directions in HCI, Amsterdam, 2004.

[7] Vanjara P. Application of mobile technologies in healthcare diagnostics and administration. In Lazakidou A ed. Handbook of Research on Informatics in Healthcare and Biomedicine, pp. 113-30. Hershey, PA: Idea Group, 2006.

[8] R.-G. Lee, H.-S. Chen, C.-C. Lin, K.-C. Chang, and J.-H. Chen, "Home telecare system using cable television plants-an experimental field trial," IEEE Trans. Inf. Technol. Biomed., vol. 4, no. 1, pp. 37-44, Mar. 2000.

[9] M. Chuah, S. Sample, "Fitness Tour: a mobile application for combating obesity" , Proc. ACM Mobile Health Workshop (collocated with Mobihoc), May 2011. 